\title{
Index Number of Multi Fuzzy Sets
}

\author{
K. Hemabala, B. Srinivasa Kumar
}

\begin{abstract}
Multi fuzzy set theory is an extension of fuzzy set theory. In this paper we developing the theory of Index number of multi fuzzy sets. This theory is applied to medical diagnosis system and will help doctors to select the effective symptoms and could make diagnosis of diseases concern. This theory also helps in selecting right political leaders.
\end{abstract}

Keywords: Multi fuzzy sets, Index number, Index number of multi fuzzy sets.

\section{INTRODUCTION}

Fuzzy set was initiated by L.A.ZADEH in 1965. So many researchers were conducted the generalization of the notion of fuzzy sets. Fuzzy numbers are convenient for representing impecise numerical quantities in a vague environment and their comparison or ranking is very important for application purpose. Despite many methods suggested in the literature there is no single measure that is universally applicable to a wide variety of situations. This paper suggests a new method for comparing fuzzy sets based on the index number by using simple aggregate average. It seems that the medical community has recognized fuzzy set most, for their ability to introduce notion of community into deductive thinking many other, like Sanchez applied the theory of fuzzy relation to medical diagnosis system. De.et.al have studied Sanchez method of medical diagnosis using intutionistic fuzzy set Also Dr. Khyalappa R, Y.S Pawar, S.H. Dhanani applied $(\in, \in \mathrm{VQ})$ fuzzy ideals to medical diagnosis system.

The major task of medical sciences is to prevent and diagnosis of diseases, a symptom could have many differential diagnosis. At times, an in experience doctor may need other doctors or consultants experts opinion regarding two or more diseases.

In this paper we use the concept of index numbers of fuzzy sets. Using this we can find index number of patient and compare this with the expert values. This theory not only in the diagnosis system we can also apply the method to select the right politician. In this case we compare the index number of politicians with the right politician.

Manuscript published on November 30, 2019.

* Correspondence Author

Kalla Hema Bala, Research Scholar Department Of Mathematics KLEF (Deemed To Be University), Vaddeswaram, Guntur (DT), Andhra Pradesh.

Dr. B. Srinivasa Kumar, Associate Professor In The Department Of Mathematics, K L E F (Deemed To Be University ), Vaddeswaram, Guntur (DT.), Andhra Pradesh

(C) The Authors. Published by Blue Eyes Intelligence Engineering and Sciences Publication (BEIESP). This is an open access article under the CC-BY-NC-ND license

(http://creativecommons.org/licenses/by-nc-nd/4.0/)

\section{PRLIMINARIES}

\section{A. Definition}

A fuzzy subset of a universe $X$ ( a fuzzy set) is a mathematical object A described by its (generalized) characterstic function (membership function) $\mu_{\mathrm{A}}: \mathrm{X} \rightarrow[0,1]$

\section{B. Definition}

Let $\mathrm{X}$ is a non empty set. A multi fuzzy set $\mathrm{A}$ in $\mathrm{X}$ is a set of ordered sequence

$A=\left\{<x, A_{1}(x), A_{2}(x), \ldots . A_{k}(x)>: x \in X\right\}$

where $A_{j}(x) \in[0,1] \forall j=1$ to $k$

If the sequences of the membership function have $\mathrm{k}$ terms then $\mathrm{k}$ is called the dimension of $\mathrm{A}$. The set of all multi fuzzy set in $\mathrm{X}$ of dimensions $\mathrm{K}$ is denoted by $\mathrm{M}^{\mathrm{K}} \mathrm{FS}(\mathrm{X})$.

\section{Definition}

Let $A$ be a multi fuzzy set of $X$ then $A: X \rightarrow[0,1]$. Then the index of $y$ with respect to base value $x$ is given in terms of its fuzzy sets by

$$
\mathrm{I}_{\mathrm{xy}}=\frac{\sum A(y)}{\sum A(x)} \mathrm{x} 100 \quad \mathrm{x}, \mathrm{y} \in \mathrm{X}
$$

\section{Definition}

Let $A$ and $B$ two multi fuzzy sets of $X$ then the index of $B$ with respect to $A$ is given by $\mathrm{I}_{\mathrm{AB}}=\frac{\sum B(x)}{\sum A(x)} \mathrm{x} 100 \quad \mathrm{x} \in \mathrm{X}$

\section{APPLICATIONS}

\section{A. Application}

\section{Algorithm}

Index number method can be applied in general by following algorithm as

1) Record values of test taken by patient during diagnosis.

2) Fuzzify the recorded value to get $A$

3) Input the values Pi given by expert which tell us about how much the test useful to identify diseases based on their knowledge and experience.

4) The values of $P_{i}$ can be taken as base value

5) Finding index number of $A$ with respect to $P_{i}$ by using

$$
\begin{aligned}
\mathrm{I}_{\mathrm{PiA}}=\frac{\sum A}{\sum P i} & \times 100 \\
& \text { Take index }
\end{aligned}
$$




\section{Index Number of Multi Fuzzy Sets}

number of base value is $100 \%$

6) Finding deviations of $\mathrm{A}$ from the base value of $\mathrm{P}_{\mathrm{i}}$ (i.e $\left.\left|\mathrm{I}_{\mathrm{pi}}-\mathrm{I}_{\mathrm{PiA}}\right|\right)$

\section{Case: 1}

40 years male patient came with complaint of chill \& rigors, body pain, head ache, weakness, fever with irregular high temperature. The doctor initially assumed
7) Minimum deviation value concludes that the patient A suffers from disease $\mathrm{P}_{\mathrm{i}}$

some possible fevers such as Malaria $\left(\mathrm{P}_{1}\right)$, Typhoid $\left(\mathrm{P}_{2}\right)$, Dengue $\left(\mathrm{P}_{3}\right)$. For confirmation, he advised patient for the following tests

\begin{tabular}{|c|c|c|c|c|c|c|c|}
\hline SL.NO & TEST & VALUES & NORMAL VALUES & $\mathbf{A i}$ & $\mathbf{P}_{1}$ & $\mathbf{P}_{2}$ & $\mathbf{P}_{3}$ \\
\hline 1 & Hemoglobin (gm\%) & 7 & $13-15$ & 0.8 & 0.6 & 0 & 0 \\
\hline 2 & ESR mm & 42 & $25-40$ & 1 & 1 & 0.8 & 0.7 \\
\hline 3 & TC & 13000 & $4000-110000$ & 1 & 1 & 0 & 0.6 \\
\hline 4 & Polymorphs & 72 & $42-70$ & 1 & 1 & 0 & 0 \\
\hline 5 & Lymphocytes & 18 & $20-45$ & 0.8 & 0 & 0 & 0 \\
\hline 6 & Monocytes & 2 & $2-8$ & 0 & 0.2 & 0.1 & 0 \\
\hline 7 & Eosnophils & 8 & $1-6$ & 1 & 0 & 0 & 0 \\
\hline 8 & P.Vivax & Abnormal & NORMAL/ABNORMAL & 1 & 1 & 0 & 0 \\
\hline 9 & Falci Form & Normal & NORMAL/ABNORMAL & 0 & 0 & 0 & 0 \\
\hline 10 & Typhoid & Normal & NORMAL/ABNORMAL & 0 & 0 & 1 & 0 \\
\hline 11 & Dengue & Normal & NORMAL/ABNORMAL & 0 & 0 & 0 & 1 \\
\hline 12 & Platelets & 2.7 lakhs & 1.5lakhs-4 lakhs & 0.6 & 0.7 & 0.7 & 1 \\
\hline
\end{tabular}

The fuzzy set defined for various best are given below

$$
\begin{aligned}
\mathrm{A}_{1}(\mathrm{x}) & =\frac{13-x}{8} & & \text { if } 5 \leq \mathrm{x} \leq 13 \\
& =1 & & , \mathrm{x}<5 \\
& =0 & & \text {, else } \\
\mathrm{A}_{2}(\mathrm{x}) & =\frac{x-14}{26} & & 14 \leq \mathrm{x} \leq 40 \\
& =1 & & , \mathrm{x}>40 \\
& =0 & & \text {, else }
\end{aligned}
$$

$$
\begin{aligned}
\mathrm{A}_{3}(\mathrm{x}) & = & \frac{12000-x}{2000}, & 10000 \leq \mathrm{x} \leq 12000 \\
& =1 & & \mathrm{x}>12000 \\
& =0 & & \text { else }
\end{aligned}
$$$$
\begin{aligned}
\mathrm{A}_{4}(\mathrm{x}) & =\frac{70-x}{40} & & , 30 \leq \mathrm{x} \leq 70 \\
& =1 & & , \mathrm{x}>70 \\
& =0 & & \text {, else }
\end{aligned}
$$$$
\mathrm{A}_{5}(\mathrm{x})=\frac{45-x}{35}, 10 \leq \mathrm{x} \leq 45
$$$$
=1 \quad, \mathrm{x}>45
$$$$
=0 \text {, else }
$$

$$
\begin{aligned}
\mathrm{A}_{6}(\mathrm{x}) & =\frac{x-2}{8} & & , 2 \leq \mathrm{x} \leq 10 \\
& =1 & & , \mathrm{x}>10 \\
& =0 & & \text {, else }
\end{aligned}
$$$$
\begin{array}{rlrl}
A_{7}(x) & =\frac{6-x}{6}, 0 \leq x \leq 6 \\
& =1, \quad x>6 \\
& =0, & \text {, else }
\end{array}
$$

$\begin{array}{rlr}\mathrm{A}_{8}(\mathrm{x}) & =1 & \text { Abnormal } \\ & =0 & \text { Normal }\end{array}$

$\begin{aligned} \mathrm{A}_{9}(\mathrm{x}) & =1 & & \text { Abnormal } \\ & =0 & & \text { Normal }\end{aligned}$

$\begin{aligned} \mathrm{A}_{10}(\mathrm{x}) & =1 & & \text { Abnormal } \\ & =0 & & \text { Normal }\end{aligned}$

$$
\begin{aligned}
\mathrm{A}_{11}(\mathrm{x}) & =1 & & \text { Abnormal } \\
& =0 & & \text { Normal } \\
\mathrm{A}_{12}(\mathrm{x}) & =\frac{x-1}{3} & & , 1 \leq \mathrm{x} \leq 4 \\
& =1 & & , \mathrm{x}<1 \\
& =0 & & \text {, else }
\end{aligned}
$$




$$
\mathrm{I}_{\mathrm{P} 1 \mathrm{~A}}=\frac{\sum A}{\sum P 1} \times 100=\frac{.8+1+1+1+0.8+1+1+0.6}{0.6+1+1+1+0.2+1+0.7} \times 100=\left|\mathrm{I}_{\mathrm{P} 1}-\mathrm{I}_{\mathrm{P} 1 \mathrm{~A}}\right|=|100-130.9|=30.9
$$

$\frac{7.2}{5.5} \times 100=130.9$

$$
\mathrm{I}_{\mathrm{P} 2 \mathrm{~A}}=\frac{\sum A}{\sum P 2} \times 100=\frac{.8+1+1+1+0.8+1+1+0.6}{0.8+0.1+1+0.7} \times 100=
$$

$\frac{7.2}{2.6} \times 100=276.9$

$$
\mathrm{I}_{\mathrm{P} 3 \mathrm{~A}}=\frac{\sum A}{\sum P 3} \quad \mathrm{x} 100=\frac{.8+1+1+1+0.8+1+1+0.6}{0.7+0.6+1+1} \times 100=
$$

$\left|\mathrm{I}_{\mathrm{P} 2}-\mathrm{I}_{\mathrm{P} 2 \mathrm{~A}}\right|=|100-276.9|=176.9$

$\left|\mathrm{I}_{\mathrm{P} 3}-\mathrm{I}_{\mathrm{P} 3 \mathrm{~A}}\right|=|100-218.1|=118.1$

\section{Result:}

Patient suffers with malaria

Case: 2

A patient 42 years age of female came with Tingling, Numbness. Let P1 denotes Diabetic, P2 denotes neuropaths, P3 denotes paler

\begin{tabular}{|l|l|l|l|l|l|l|l|}
\hline SL.NO & \multicolumn{1}{|c|}{ TEST } & VALUES & \multicolumn{1}{|c|}{ NORMAL VALUES } & $\mathbf{A i}$ & $\mathbf{P}_{\mathbf{1}}$ & $\mathbf{P}_{\mathbf{2}}$ & $\mathbf{P}_{\mathbf{3}}$ \\
\hline 1 & Hemoglobin (gm\%) & 6 & $13-15$ & 0.9 & 0 & 0 & 0.6 \\
\hline 2 & FBS(mg) & 80 & $70-100$ & 0.8 & 0.1 & 0.7 & 0.7 \\
\hline 3 & PPBS & 140 & $100-160$ & 0 & 0.3 & 0 & 0 \\
\hline 4 & Nerve Conduction Test & ABNORMAL & NORMAL/ABNORMAL & 1 & 0 & 0 & 1 \\
\hline
\end{tabular}

The fuzzy set defined for various test are given below

$$
\begin{aligned}
& \begin{aligned}
\mathrm{A}_{1}(\mathrm{x}) & =\frac{13-x}{8} & & , \text { if } 5 \leq \mathrm{x} \leq 13 \\
& =1 & & , \mathrm{x}<5 \\
& =0 & & \text {, else }
\end{aligned} \\
& \mathrm{A}_{2}(\mathrm{x})=\frac{150-x}{90}, 60 \leq \mathrm{x} \leq 150 \\
& =1 \quad, \mathrm{x}>150 \\
& =0 \text {, else }
\end{aligned}
$$

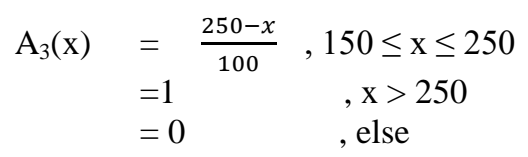

$$
\begin{aligned}
& \mathrm{A}_{4}(\mathrm{x}) \quad=1 \quad \text { Abnormal } \\
& =0 \quad \text { Normal } \\
& \mathrm{I}_{\mathrm{P} 1 \mathrm{~A}}=\frac{\sum A}{\sum P 1} \times 100=\frac{0.9+0.8+1}{0.1+0.3} \times 100=\frac{2.7}{0.4} \times 100=675 \\
& \mathrm{I}_{\mathrm{P} 2 \mathrm{~A}}=\frac{\sum A}{\sum P 2} \times 100=\frac{0.9+0.8+1}{0.7} \times 100=\frac{2.7}{0.7} \times 100=385.7 \\
& \mathrm{I}_{\mathrm{P} 3 \mathrm{~A}}=\frac{\sum A}{\sum P 3} \times 100=\frac{0.9+0.8+1}{0.6+0.7+1} \times 100=\frac{2.7}{2.3} \times 100=117.4
\end{aligned}
$$

$\left|\mathrm{I}_{\mathrm{P} 1}-\mathrm{I}_{\mathrm{P} 1 \mathrm{~A}}\right|=|100-675|=575$

$$
\left|\mathrm{I}_{\mathrm{P} 2}-\mathrm{I}_{\mathrm{P} 2 \mathrm{~A}}\right|=|100-385.7|=285.7
$$

$\left|\mathrm{I}_{\mathrm{P} 3}-\mathrm{I}_{\mathrm{P} 3 \mathrm{~A}}\right|=|100-117.4|=17.4$

\section{Result:}

Patient suffers with paler

Note: P1, P2, P3 values given by expert which tell us about how much the test useful to identity diseases based on their knowledge

\section{B. APPLICATION}

The second application of index number is selecting political candidates. Parties can select their candidates in many different ways. In numerous cases, the existing legal frame work establishes that the political parties should democratically elect their candidates, but this concept is very vague, and there are few if any applicable legal provisions only in a few cases does legislation lay down the process by which the candidates should be selected and the selection process can have a direct impact on the depth and breadth of the democratic process: particularly if a given party's candidate selection process is non transparent Using this theory we compare candidates (Pi) index number to the good qualities of candidate (A) index number. Generally $\mathrm{P}$ be the base. Factors such as electoral system, party ideology, political culture and the organizational government have been thought to have an influence on the centralization and participation in the candidates selection process.

Following factors are considered for the selection of candidates

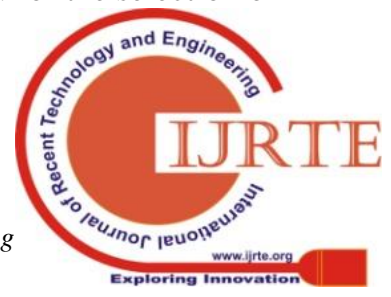


Index Number of Multi Fuzzy Sets
1. Behavior
2. Age
3. Character
4. Publicity
5. Education

\section{Algorithm}

Index number method can be applied in general by following algorithm as

1. Set the good qualities of the leader like behavior, age, character, publicity, education by party leader

2. Fuzzify the recorded value to get $\mathrm{A}$

3. Input the value of candidates for the selection and fuzzify these values to get $\mathrm{Pi}$

4. The values of A can be taken as base value

5. Finding index numbers of $\mathrm{p}_{\mathrm{i}}$ with respect to $\mathrm{A}$ by using

$\mathrm{I}_{\mathrm{APi}}=\frac{\sum \mathrm{Pi}}{\sum \mathrm{A}} \times 100$

Take index number of base value $\mathrm{I}_{\mathrm{A}}$ is $100 \%$

6. Finding deviations of $\mathrm{p}_{\mathrm{i}}$ from the base value of $\mathrm{A}$ (i.e $\left.\left|\mathrm{I}_{\mathrm{A}}-\mathrm{I}_{\mathrm{APi}}\right|\right)$

7. Minimum deviation value gives the better qualities of the politician, hence we can conclude $\mathrm{P}_{\mathrm{i}}$ for the party candidate

\section{CONCLUSION}

This theory of Index number will help doctors to select the effective symptoms and could make diagnosis of the disease concern. Also this theory most widely help to output (Industrial Production, Agriculture Production), volume of imports and export. An index number is a relative number which expresses the relationship between two variables or two groups of variables where one of the group used as base.

\section{ACKNOWLEDGMENT}

One of the authors K. Hemabala thanks to Prof. AVSN Murthy from Vellore Institute of Technology, Vellore for constant encouragement and support to carry on this work.

\section{REFERENCES}

1. George J. Klir/Bo Yuan, Fuzzy sets and Fuzzy logic, ISBN -978-81-203-1136-7(1995), pp: 50-94

2. A. Rosenfeld, Fuzzy groups, J. Math Anal. Appl. 35:512-517(1971)

3. L.A. Zadeh Fuzzy sets information and control 8,338-348(1965)

4. Sabu Sebastian, T.V. Ramakrishnan, Multi Fuzzy sets, International mathematics forum, 5(2010), number 50, pp: 2471-2476.

5. S.K. De, R. Biswas, A.R. Roy, An application of intuitionistic fuzzy sets in medical diagnosis, Fuzzy sets and systems 117(2001),209-213.

6. S.Sabu and T.V.Ramakrishnan, Multi fuzzy topology, Internatiional journal of Applied Mathematics.

7. S.Sabu and T,V.Ramakrishnan, Multi fuzzy subgroups, Int.J.Contemp.Math.Sciences,6(8)(2011),365-372.

8. Fundamentals Of Business Mathematics Statistics[FMS],P4,Directorate of Studies,2014,pp:7.1-7.21.

9. Srinivasa Rao, T., Suresh Kumar, G., Vasavi, C., \& Murty, M. S. N. (2016). Observability of fuzzy difference control systems. International Journal of Chemical Sciences, 14(4), 2516-2526.

10. Vasavi, C., Suresh Kumar, G., \& Murty, M. S. N. (2016). Fuzzy dynamic equations on time scales under generalized delta derivative via contractive-like mapping principles. Indian Journal of Science and Technology, 9(25) doi:10.17485/ijst/2016/v9i25/85323

11. Vasavi, C., Suresh Kumar, G., \& Murty, M. S. N. (2016). Fuzzy hukuhara delta differential and applications to fuzzy dynamic equations on time scales. Journal of Uncertain Systems, 10(3), 163-180.

12. Vasavi, C., Suresh Kumar, G., \& Murty, M. S. N. (2016). Generalized differentiability and integrability for fuzzy set-valued functions on time scales. Soft Computing, 20(3),

doi:10.1007/s00500-014-1569-1

13. Vasavi, C. H., Suresh Kumar, G., \& Murty, M. S. N. (2016). Fuzzy dynamic equations on time scales under second type hukuhara delta derivative. International Journal of Chemical Sciences, 14(1), 49-66.

14. Lakshmana Gomathi Nayagam, V., Jeevaraj, S., \& Dhanasekaran, P. (2016). A linear ordering on the class of trapezoidal intuitionistic fuzzy numbers. Expert Systems with Applications, 60, 269-279. doi:10.1016/j.eswa.2016.05.003

15. Nayagam, V. L. G., Dhanasekaran, P., \& Jeevaraj, S. (2016). A complete ranking of incomplete trapezoidal information. Journal of Intelligent and Fuzzy Systems, 30(6), 3209-3225. doi:10.3233/IFS-152064

16. Rao, T. S., Kumar, G. S., Vasavi, C., \& Rao, B. V. A. (2017). On the controllability of fuzzy difference control systems. International Journal of Civil Engineering and Technology, 8(12), 723-732.

17. Vasavi, C. H., Kumar, G. S., Rao, T. S., \& Rao, B. V. A. (2017). Application of fuzzy differential equations for cooling problems. International Journal of Mechanical Engineering and Technology, 8(12), 712-721.

18. Bhargavi, Y., \& Eswarlal, T. (2016). Application of vague set in medical diagnosis. International Journal of Chemical Sciences, 14(2), 842-846

19. Bhargavi, Y., \& Eswarlal, T. (2016). Vague magnified translation in $\Gamma$-semirings. International Journal of Pure and Applied Mathematics, 106(2), 453-460. doi:10.12732/ijpam.v106i2.9.

20. Amarendra Babu, V., \& Anitha, T. (2016). Vague prime LI-ideals of lattice implication algebras. International Journal of Pure and Applied Mathematics, 107(1), 35-48. doi:10.12732/ijpam.v107i1.4

\section{AUTHORS PROFILE}

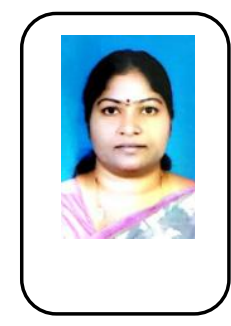

Kalla Hema Bala completed M. Sc (Mathematics) in the year 1998 from Pondicherry University, M Phil (Mathematics) in the year 2005 from Madhurai Kamaraj University and M. Tech(Computer Science ) in the year 2014 from JNTU. I am research scholar in the department of Mathematics KLEF (Deemed to be University), Vaddeswaram, Guntur (DT), Andhra Pradesh. Further I am working in Multi fuzzy ideals of rings.

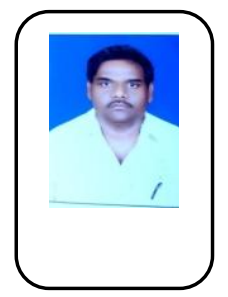

Dr. B. Srinivasa Kumar completed his Ph.D in the year 2015 from Koneru Lakshmaiah Education Foundation. Dr. Kumar is presently working as an Associate professor in the department of Mathematics, K L E F (Deemed to be University ), Vaddeswaram, Guntur (DT.), Andhra Pradesh.He published 25 Research articles in various national and international indexed journals. 